\title{
Awareness of polycystic ovarian syndrome among young women in Western India
}

\author{
Esha G. Chainani* \\ Department of Obstetrics and Gynecology, D.Y. Patil School of Medicine, Navi Mumbai, Maharashtra, India
}

Received: 27 July 2019

Accepted: 25 October 2019

\section{*Correspondence:}

Dr. Esha G. Chainani,

E-mail: eshachainani@hotmail.com

Copyright: () the author(s), publisher and licensee Medip Academy. This is an open-access article distributed under the terms of the Creative Commons Attribution Non-Commercial License, which permits unrestricted non-commercial use, distribution, and reproduction in any medium, provided the original work is properly cited.

\begin{abstract}
Background: Polycystic ovary syndrome (PCOS) is a complex condition characterized by elevated androgen levels, menstrual irregularities, and/or small cysts on one or both ovaries. It is a common issue affecting more than $7 \%$ of adult women, causing many problems including but not limited to infertility, irregular menses, hirsutism, acne and alopecia. The primary cause of PCOS is still unknown but awareness and lifestyle modification is known to be an efficient therapy route to relieve symptoms of this syndrome. Objective of the study was to assess the knowledge about PCOS in young women in Navi Mumbai, Maharashtra, India.

Methods: A cross sectional study was performed on 500 women of age group 18-30 years coming to outpatient departments of D. Y. Patil Hospital, Navi Mumbai. Written informed consent was obtained and simple random technique was applied for selection of study participants. Pre-designed, pre-tested, semi-structured questionnaire was used for data collection. The data collected was analyzed through percentages and frequencies using Excel. Relevant statistical test was applied was applied and $\mathrm{p}$ value was calculated wherever required and considered statistically significant when $<0.05$.

Results: Among 500 participants, only $38 \%$ of the women were aware of the term PCOS. $26 \%$ of the subjects were aware about the organ system involved in this disease. Most of the people know about this disorder through friends or relatives. $17 \%$ of the women knew about the various symptoms associated with PCOS.

Conclusions: The alarming results of present study show that very small number of young women understand what this disease is and thus when to consult a physician. This could be why PCOS is an underrepresented and underdiagnosed disease. This widely prevalent disease among young women should be talked about more and more young women must be educated on this to help prevent the sequelae of this syndrome on fertility and insulin resistance.
\end{abstract}

Keywords: Awareness, India, Polycystic ovary syndrome, Women

\section{INTRODUCTION}

Polycystic ovary syndrome (PCOS) is a complex condition characterized by elevated androgen levels, menstrual irregularities, and/or small cysts on one or both ovaries. Polycystic ovary syndrome (PCOS) is a common condition, present in $12-21 \%$ of women of reproductive age, depending on the criteria used and the population assessed causing many problems including but not limited to infertility, irregular menses, hirsutism, acne and alopecia. ${ }^{1}$

Changing definitions and a range of symptoms have made the path to diagnosis for many women difficult; up to $70 \%$ of women with PCOS in the community remain undiagnosed. ${ }^{1}$ In India, it is much underrepresented disease to the common population and not much 
discussed so many women go undiagnosed with multiple worrying results.

As far as the definition of PCOS goes, the Rotterdam criteria was the most widely accepted across the world and is the definition used for the guideline. It encompasses the National Institutes of Health definition, which generally describes women with a more severe form of PCOS and requires the presence of both hyperandrogenism and oligo/anovulation. The Rotterdam Criteria require the presence of two of the following: oligo/anovulation, hyperandrogenism or polycystic ovaries on ultrasound. ${ }^{2}$

Two of the following three criteria are required for Rotterdam diagnosis of polycystic ovary syndrome:

- Oligo/anovulation

- Hyperandrogenism

- Clinical (hirsutism or less commonly male pattern alopecia) or

- Biochemical (raised FAI or free testosterone)

- Polycystic ovaries on ultrasound

- Other aetiologies must be excluded such as congenital adrenal hyperplasia, androgen secreting tumours, cushing syndrome, thyroid dysfunction and hyperprolactinaemia.

There is a range of symptoms that women present with and these can vary with age. Reproductive symptoms predominate in younger women. The prevalence of metabolic features increases with age but can also occur in overweight young women.

Hyperandrogenaemia and insulin resistance are pathophysiological features of PCOS.

- Hirsutism and male pattern balding consistent with hyperandrogenism

- Irregular or absent menstrual cycles

- Subfertility or infertility

- Psychological symptoms - anxiety, depression, psychosexual dysfunction, eating disorders.

Women are at risk if they have a genetic predisposition, and the onset of symptoms can be triggered by environmental factors, particularly obesity. It is important to be aware that some population groups have a higher risk of PCOS and different populations may have predispositions to different symptoms.

PCOS appears to be a particularly common endocrine disorder in the world population under study; furthermore, it is associated with certain metabolic abnormalities. $^{3-5}$

India has witnessed a sudden rise in PCOS and infertility cases in the last couple of years and that is only the tip of the iceberg. Lack of knowledge, rampant obesity, increase in a sedentary lifestyle and lack of exercise seem to be major factors leading to this rise. Awareness among women is also at a low as many women do not seem to know about this condition and this is found as an incidental finding to infertility and/or irregular menses. Adolescents are also showing an increase in incidence of PCOS and the belief is that raised awareness can lead to early diagnosis and maybe even prevention of PCOS. ${ }^{6}$

\section{METHODS}

A cross sectional study was performed on 500 women of age group 18-30 years coming to Out Patient Departments of D. Y. Patil Hospital, Navi Mumbai. Duration of the study was 2 months from Septemer 2018 to November 2018. Written informed consent was obtained. A simple random sampling method was used to pick subjects for the study. Pre-designed, pre-tested, semi-structured questionnaire was used for data collection before knowledge awareness intervention. Incomplete questionnaires were excluded from the study. The data collected was analyzed through percentages and frequencies using Excel. Relevant statistical test was applied was applied and p-value was calculated where ever required and considered statistically significant when $<0.05$.

\section{Inclusion criteria}

- Women of age group 18-30 years, those who gave written consent.

\section{Exclusion criteria}

- Women of age group of less than 18 years and more than 30 years.

- Women not giving written consent.

\section{Statistical analysis}

Relevant statistical test (Chi-square) was applied and $\mathrm{p}$ value was calculated where required and considered statistically significant when $<0.05$.

\section{RESULTS}

During the study interval 523 responses to the questionnaire were registered. 20 responses were incomplete and were excluded, 3 responses were excluded due to incomplete consent forms. $37.4 \%$ women were in the age group of 18-24 years and $62.6 \%$ women in the age group of 25-30 years (Table 1).

Among 500 participants, only 38\% of the women were aware of the term PCOS. 26\% of the subjects were aware about the organ system involved in this disease (Table 2).

Out of the 190 women aware of the term PCOS, the most common presentation for PCOS was asymptomatic $(\mathrm{n}=$ 
79) followed by irregular menses, infertility, obseity, hirsutism followed by psychological disorders (Figure 1).

Table 1: Age group distribution.

\begin{tabular}{|l|l|l|}
\hline $\begin{array}{l}\text { Age group } \\
\text { (in years) }\end{array}$ & $\begin{array}{l}\text { Number of } \\
\text { patients }\end{array}$ & Percent (\%) \\
\hline $18-24$ & 187 & 37.4 \\
\hline $25-30$ & 313 & 62.6 \\
\hline
\end{tabular}

Table 2: Awareness of term PCOS.

\begin{tabular}{|l|l|l|}
\hline Patient & Number & Percent (\%) \\
\hline Aware of term PCOS & 190 & 38 \\
\hline Unaware of term PCOS & 310 & 62 \\
\hline
\end{tabular}

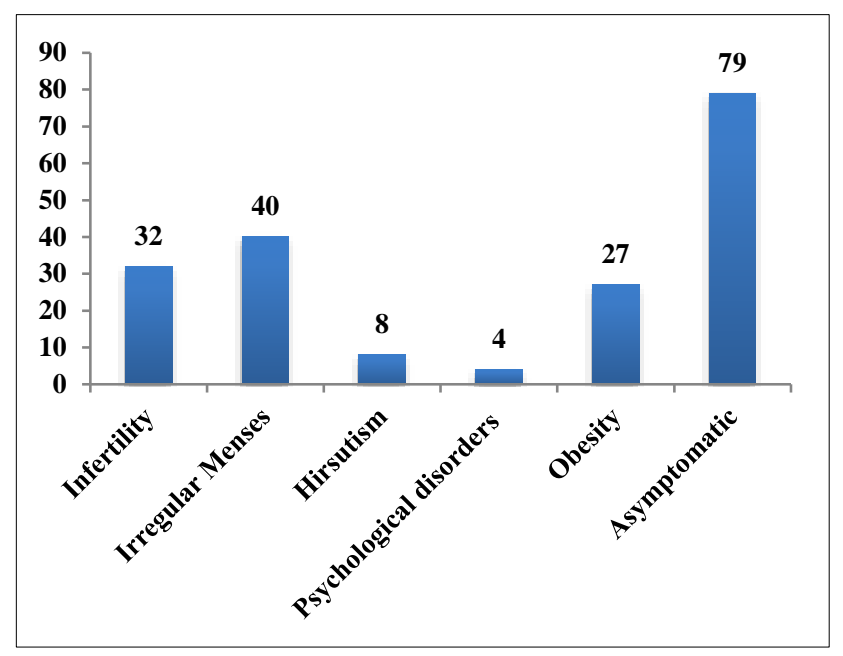

Figure 1: Symptomatology associated with PCOS.

The study participants knew about the term PCOS due to doctors visits followed by Media/Internet sources, Friends, Teachers and then family (Figure 2).

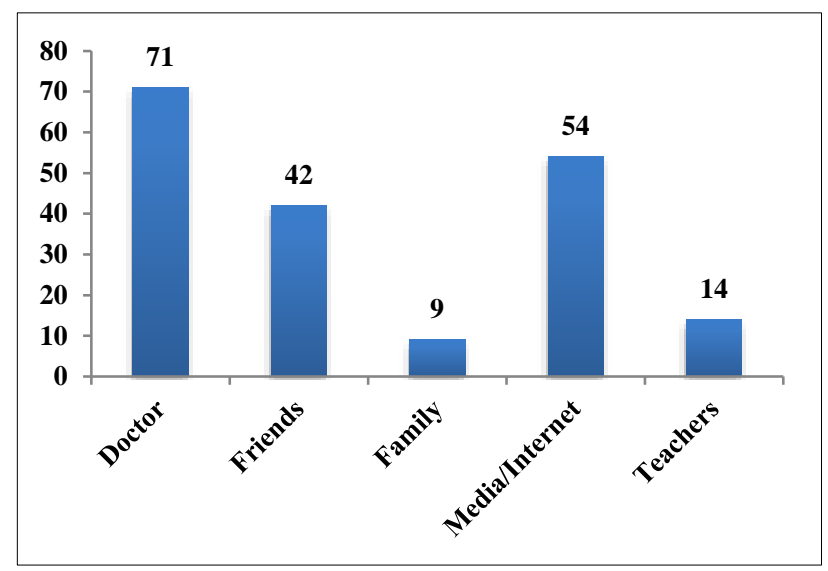

Figure 2: Sources of knowledge of PCOS.

A $72 \%$ of the people did not know about the role of lifestyle changes like diet, lack of physical activities, stress and obesity are that are involved in the pathogenesis of the disorder.
Only $28 \%$ of the subjects are regularly involved in some kind of exercise. Almost $42 \%$ of the subjects were struggling with difficulty in losing weight.

Women were also asked about the time interval between their last Obstetrician Gynecologist visit and the results were stacked according to their age group. Most women in the age group of 18-24 years had not visited an OBGYN at all and most women in the age group of 2530 years had visited an OBGYN in the last 6 months (Figure 3).

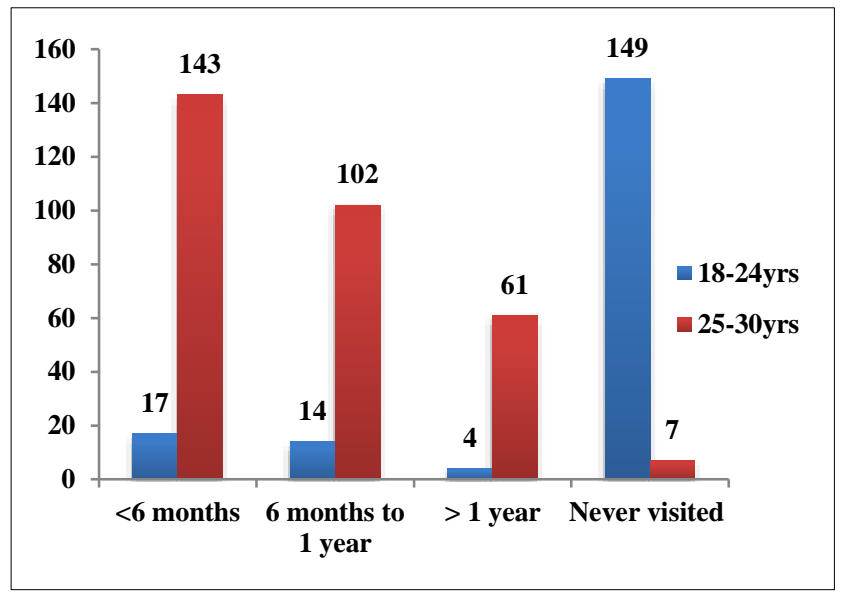

Figure 3: Time interval between last OBGYN visit.

The most common self reported reason for visiting an OBGYN in the age group 18-24 years was irregular menses followed by pregnancy and in the age group of 25-30 was pregnancy followed by inability to conceive. A total of 1 woman in the entire study reported coming for a regular checkup (Figure 4).

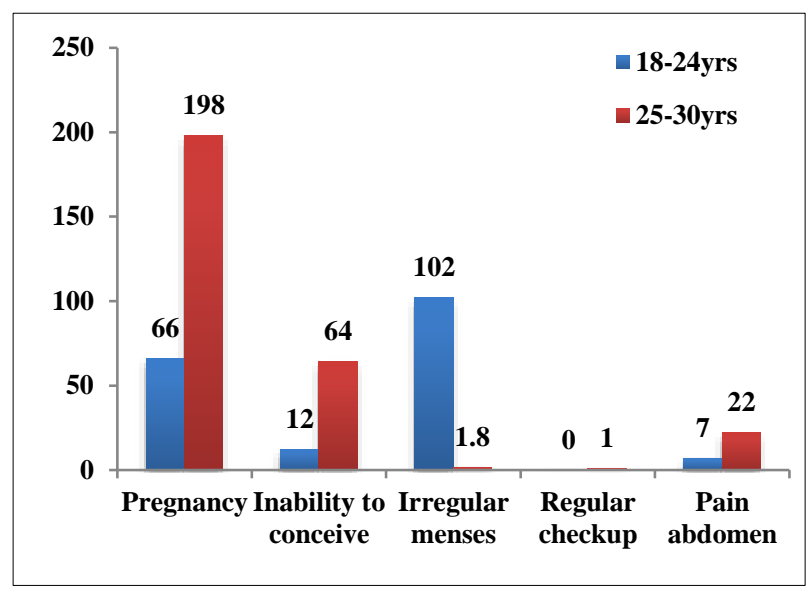

Figure 4: Most common self reported reason for visiting an OBGYN.

\section{DISCUSSION}

Polycystic ovary syndrome (PCOS) is a convergence of chronic multisystem endocrine aberrations, including irregular menses, hirsutism, obesity, hyperlipidemia, 
androgenization, large and polycystic-appearing ovaries, insulin resistance and infertility. ${ }^{7}$ Although PCOS is the most common hormonal disorder among reproductive age women it is the leading cause for anovulatory/ oligoovulatory infertility and has the potential for serious long-term health effects. PCOS is posited to be the most common endocrine abnormality of reproductive-aged women in the United States. ${ }^{8}$ The absence of uniform diagnostic criteria for PCOS and lack of any pulbicization, education and awareness of this disease has probably contributed to its low clinical diagnosis rate. If the objective of heightened public interest in PCOS is indeed achieved through wide public service announcements or other structured media exposure, then it could lead to a higher awareness and therefore prevention of this disease complex.

In present study only $38 \%$ of the women were aware of the term PCOS, $17 \%$ of the subjects who were aware knew about the organ system involved in this disease. A similar study by Safa showed that $50 \%$ have knowledge about the PCOS and in contrast to present study only $6 \%$ aware about the reasons and consequences of the condition. ${ }^{9}$ Another survey by Ansari et al found only $10 \%$ of their study population having knowledge of PCOS. A study by Sabitha et al revealed that $76 \%$ had average knowledge about PCOS but $10 \%$ actually knew about the organ systems and pathology of the disease. ${ }^{10}$ Abbas et al found in there study $45 \%$ are aware of PCOS condition which is similar to present finding. ${ }^{11}$ Sunanda B et al found that $76 \%$ of the samples were with average knowledge and $10.7 \%$ with good knowledge regarding polycystic ovarian syndrome. ${ }^{12} \mathrm{Gul} \mathrm{S}$ et al found that only 20 out of 177 women had any knowledge about this syndrome. 19 Out of these 20 women 11 were those who had degrees in Medical Sciences. ${ }^{6}$

This study also revealed that most of the study subjects know about this disorder through their doctor followed by media/internet. A study performed on polycystic ovarian syndrome in adolescents in Rotterdam showed that $11.5 \%$ of the population got knowledge from a doctor and 5\% learnt from the internet Jayshree et $\mathrm{al}^{[13]}$, another study shows information source $51 \%$ from doctor and $22 \%$ form internet Pitchai et al. ${ }^{14}$ A study conducted in Sri Lanka posited the most common phenotypes of PCOS were oligo/amenorrhea and polycystic ovaries (91.4\%) and oligo/amenorrhea and hirsutism $(48.3 \%) .{ }^{15}$

A two year follow up study in adoloscents showed a statistically significant higher percentage difference in prevalence of irregular menses $(59.9 \%)$, hirsuitism $(56.3 \%)$, acne $(17.8 \%)$, obesity $(17.3 \%)$, polycystic ovaries on ultrasound $(47.8 \%)$ and clinical hyperandrogenism $(56.1 \%)$ among those with PCOS as against those without PCOS. ${ }^{16}$

Very few of the studied females were aware of the effect of doing excises, decreasing the weight, using contraceptives, and eating fruit and vegetables on reliving
PCOS symptoms. Most participants were unaware of the long-term complications as hypertension, diabetes mellitus, and cardiovascular abnormality. They were mostly unaware of its relationship to early puberty and inheritance as well.

Most of the studied females did not know about the role of lifestyle changes like diet, lack of physical activities, stress and obesity are that are involved in the pathogenesis of the disorder. Even fewer females are regularly involved in some kind of exercise. Almost $42 \%$ of the subjects were struggling with difficulty in losing weight.

The importance of understanding the full spectrum of PCOS is as presented to different specialty clinics. Not only is the syndrome under diagnosed but also are the significant associated morbidities such as IGT and type 2 diabetes. ${ }^{17}$ Women with PCOS had higher levels of luteinizing hormone and higher luteinizing hormone/follicle-stimulating hormone ratios than those in the other groups. ${ }^{18}$ A study in China comparing the 833 women with PCOS to 2732 women without PCOS indicated that PCOS occurs in younger women and these women were prone not only to menstrual problems, hyperandrogenism, PCO and infertility but also metabolic syndrome and insulin resistance. ${ }^{19}$ Different specialists need to appreciate the spectrum of health problems for women with PCOS that may extend beyond the specific symptoms that precipitated the initial referral.

As with any questionnaire-based research, there were some limitations with the study that should be acknowledged. The research method relied on an unscreened and unmotivated audience and their educational background was not screened which could lead to some false negatives and positive answers not accounted for and corrected in the study.

\section{CONCLUSION}

The alarming results of present study show that very small number of young women understand what polycystic ovarian syndrome is and thus when to consult a physician. This could be why PCOS is an underrepresented and underdiagnosed disease. This widely prevalent disease among young women should be talked about more and more young women must be educated on this to help prevent the sequelae of this syndrome on fertility and insulin resistance.

\section{Funding: No funding sources \\ Conflict of interest: None declared \\ Ethical approval: Not Required}

\section{REFERENCES}

1. Rotterdam ESHRE/ASRM-Sponsored. PCOS Consensus Workshop Group. Revised 2003 consensus on diagnostic criteria and long-term health risks 
related to polycystic ovary syndrome. Hum Reprod. 2004;19:41-7.

2. Revised 2003 consensus on diagnostic criteria and long-term health risks related to polycystic ovary syndrome. Fertil Steril. 2004;81:19-25.

3. Knochenhauer ES, Key TJ, Miller M, Waggoner W, Boots LR, Azziz R. Prevalence of the polycystic ovary syndrome in unselected black and white women of the southeastern United States: A prospective study. J Clin Endocrinol Metab. 1998;83:3078-82.

4. Kandarakis DE, Kouli CR, Bergiele AT, Filandra FA, Tsianateli TC, Spina GG, et al. A survey of the polycystic ovary syndrome in the Greek Island of Lesbos: Hormonal and metabolic profile. J Clin Endocrinol Metab. 1999;84:4006-11.

5. Michelmore KF, Balen AH, Dunger DB, Vessey MP. Polycystic ovaries and associated clinical and biochemical features in young women. Clin Endocrinol. 1999;51:779-86.

6. Nidhi R, Padmalatha V, Nagarathna R, Amritanshu R. Prevalence of polycystic ovarian syndrome in Indian adolescents. J Pediatr Adolesc Gynecol. 2011;24:2237 .

7. Sills ES, Perloe M, Palermo GD. Correction of hyperinsulinemia in oligoovulatory women with clomiphene-resistant polycystic ovary syndrome: a review of therapeutic rationale and reproductive outcomes. Eur J Obstet Gynecol Reprod Biol. 2000;91(2):135-41.

8. Azziz R, Woods KS, Reyna R, Key TJ, Knochenhauer ES, Yildiz BO. The prevalence and features of the polycystic ovary syndrome in an unselected population. J Clin Endocrinol Metab. 2004;89:2745-9.

9. Jahangir S. Knowledge and awareness of polycystic ovarian syndrome among female non-medical undergraduate students. EWU Institutional Repository. 2017. Available at: http://dspace.ewubd.edu/handle/123456789/2667.

10. Homburg R. Pregnancy complications in PCOS. Best Pract Res Clin Endocrinol Metab. 2006;20(2):28192.

11. Rizvi M, Abbas A, Tanwir S, Sabah A, Ali ZM, Sundrani MM, et al. Perception and attitude of patients regarding polycystic ovarian syndrome
(PCOS) in tertiary care hospitals of Pakistan-a survey based study. Int J Pharma Therap. 2014;5(3):147-52.

12. Sunanda B, Nayak S. A study to assess the knowledge regarding PCOS (polycystic ovarian syndrome) among nursing students at NUINS. NUJHS. 2016;6(3):47-9.

13. Upadhye JJ, Shembekar CA. Awareness of PCOS (polycystic ovarian syndrome) in adolescent and young girls. Int J Reprod Contracept Obstet Gynecol. 2017;6:2297-301.

14. Pitchai P, Sreeraj SR, Anil PR. Awareness of lifestyle modification in females diagnosed with polycystic ovarian syndrome in India: explorative study. Int $\mathbf{J}$ Reprod Contracept Obstet Gynecol. 2016;5(2):470-6.

15. Kumarapeli V, Seneviratne RA, Wijeyaratne CN, Yapa RM, Dodampahala SH. A simple screening approach for assessing community prevalence and phenotypes of polycystic ovary syndrome in semiurban population in Srilanka. Am J Epidemiol. 2008;168:321-7.

16. Nair MK, Pappachan P, Balakrishnan S, Leena ML, George B, Russell PS. Menstrual irregularity and poly cystic ovarian syndrome among adolescent girls: A two year follow-up study. Indian $\mathbf{J}$ Pediatr. 2012;79(11):69-73.

17. Sivayoganathan D, Maruthini D, Glanville JM, Balen AH. Full investigation of patients with polycystic ovary syndrome (PCOS) presenting to four different clinical specialties reveals significant differences and undiagnosed morbidity. Hum Fertil. 2011;14:261-5.

18. Chen X, Yang D, Mo Y, Li L, Chen Y, Huang Y. Prevalence of polycystic ovary syndrome in unselected women from southern China. Eur J Obstet Gynecol Reprod Biol. 2008;139:59-64.

19. Li R, Zhang Q, Yang D, Li S, Lu S. Prevalence of polycystic ovary syndrome in women in China: a large community-based study. Hum Reprod. 2013;28(9):2562-9.

Cite this article as: Chainani EG. Awareness of polycystic ovarian syndrome among young women in western India. Int J Reprod Contracept Obstet Gynecol 2019;8:4716-20. 